\title{
Use of direct cholangiopancreatoscopy to identify pancreaticobiliary fistula
}

Direct cholangiopancreatoscopy for the diagnosis of a pancreaticobiliary fistula is infrequently reported $[1,2]$. We report the case of a 70-year-old man who presented with cholangitis. A magnetic resonance cholangiopancreatography revealed a complex $6.6 \mathrm{~cm}$ cystic mass in the pancreatic head and neck, inseparable from the dilated main pancreatic duct (PD), and a possible fistulous connection between the common bile duct $(C B D)$ and main PD ( $\triangleright$ Fig. 1, $\triangleright$ Video 1 ).

Endoscopic ultrasound showed a complex mixed echoic and anechoic lesion in the head of the pancreas consistent with a cyst, measuring $40 \times 56 \mathrm{~mm}$ ( $>$ Fig. 2), and communicating with the main PD.

Endoscopic visualization of the ampulla revealed obstructing mucin consistent with fish mouth sign ( $\triangleright$ Fig.3). Cholangiogram demonstrated a dilated CBD and evidence of a fistula within the midduct communicating with the pancreatic cyst. A digital cholangioscopy system (SpyGlass DS; Boston Scientific Corp., Marlborough, Massachusetts, USA) was inserted into the $C B D$, revealing mucin filling the distal duct to the bifurcation of the hepatic ducts ( $\triangleright$ Fig. 4 a). Proximal to the common hepatic duct no further mucin was seen, and the mucosa was normal. The PD was visualized using a digital cholangioscope to map the main duct lesion. There was frond-like PD mucosa throughout the head of the pancreas with mucin ( $\triangleright$ Fig. 4 b). The cholangioscope was able to pass through the main PD into the CBD through a pancreaticobiliary fistula.

Cytology revealed a high grade intraductal papillary mucinous neoplasm. An open Whipple was performed with pathology revealing moderately differentiated invasive adenocarcinoma limited to the pancreas, with high grade dysplasia that focally involved the distal CBD.
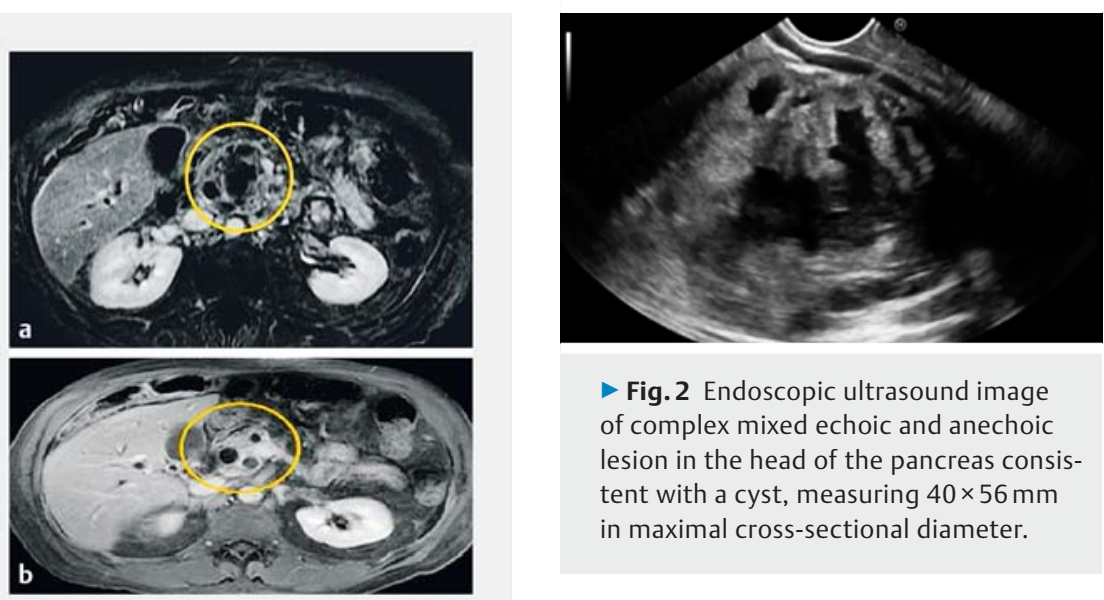

- Fig. 2 Endoscopic ultrasound image of complex mixed echoic and anechoic lesion in the head of the pancreas consistent with a cyst, measuring $40 \times 56 \mathrm{~mm}$ in maximal cross-sectional diameter.

- Fig. 1 Magnetic resonance cholangiopancreatography images. a A complex $6.6 \mathrm{~cm}$ cystic mass (yellow circle) was seen in the pancreatic head and neck, inseparable from the dilated main pancreatic duct. Dilated pancreatic side branches and moderate diffuse intra- and extrahepatic biliary ductal dilation were also seen. b The fistulous connection between the common bile duct and the main pancreatic duct at the level of the pancreatic neck (yellow circle).

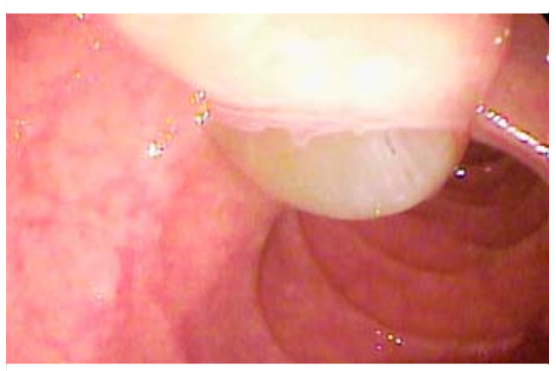

- Fig. 3 Endoscopic view of the ampulla with copious mucin discharge.

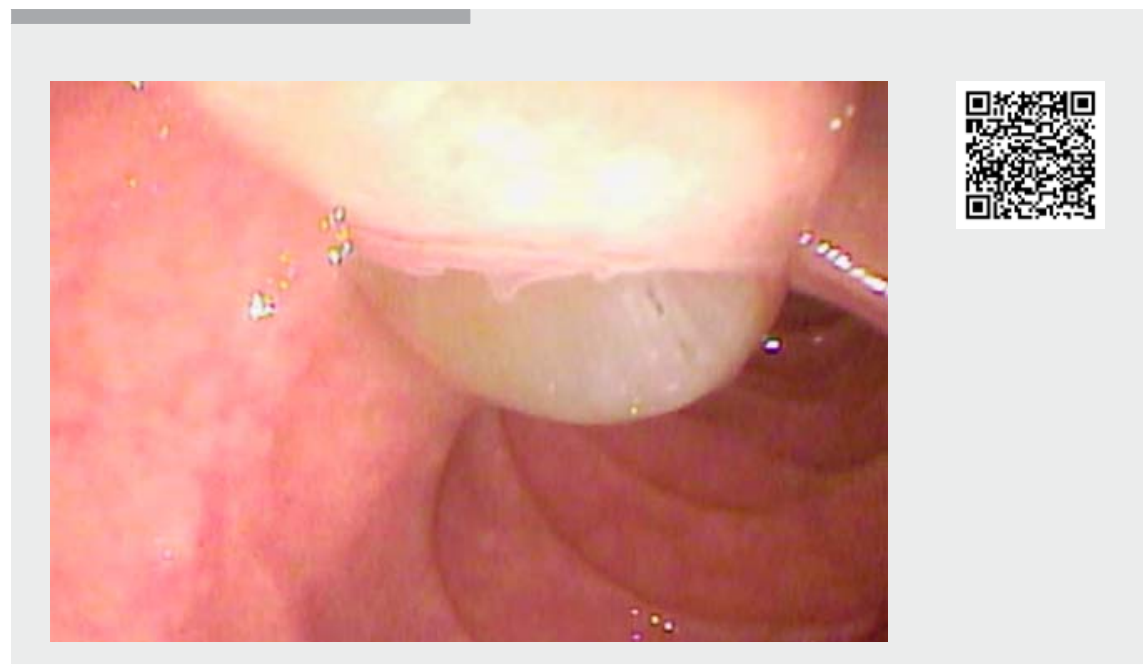

$\checkmark$ Video 1 Use of a cholangiopancreatoscopy system for the diagnosis of a mucin-producing pancreas tumor with a pancreaticobiliary fistula. 

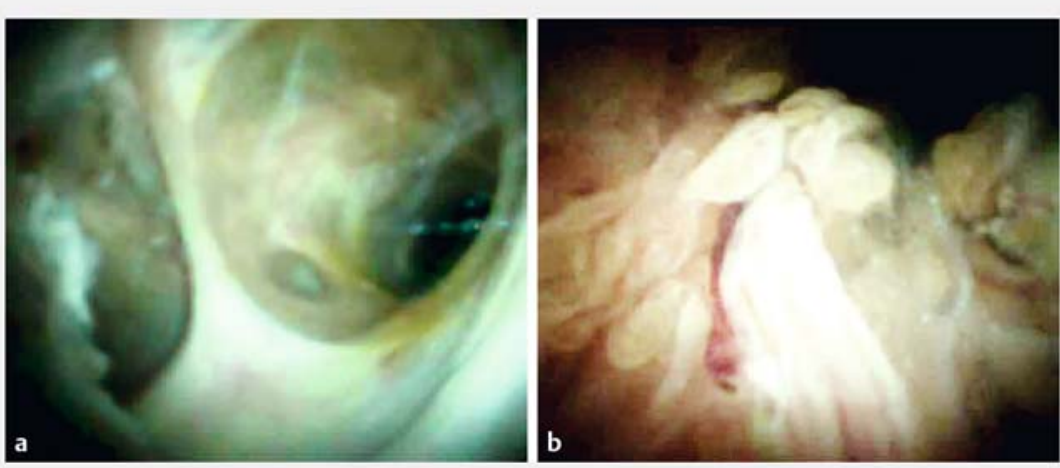

- Fig.4 Cholangiopancreatoscopy. a Cholangioscopy showed bifurcation of the hepatic ducts with no further mucin and normal common bile duct mucosa. b Pancreatoscopy showed frond-like pancreatic duct mucosa throughout the head of the pancreas with mucin.

This case demonstrates the usefulness of direct pancreatoscopy and cholangioscopy as a mapping tool for outlining the extent of malignant mucinous main duct lesions of the pancreas.

Endoscopy_UCTN_Code_CCL_1AZ_2AH

\section{Corresponding author}

Competing interests

None

\section{Nathaniel Avila, Paul Tarnasky, Prashant} Kedia

Gastroenterology, Methodist Dallas Medical Center, Dallas, Texas, United States

\section{Nathaniel Avila, MD}

Gastroenterology, Methodist Dallas Medical

\section{References}

[1] Sung KF, Chu YY, Liu NJ et al. Direct peroral cholangioscopy and pancreatoscopy for diagnosis of a pancreatobiliary fistula caused by an intraductal papillary mucinous neoplasm of the pancreas: a case report. Dig Endosc 2011; 23: 247-250

[2] Ren X, Zhu CL, Qin XF et al. Co-occurrence of IPMN and malignant IPNB complicated by a pancreatobiliary fistula: a case report and review of the literature. World J Clin Cases 2019; 7: $102-108$

\section{Bibliography}

DOI https://doi.org/10.1055/a-0929-3905

Published online: 4.7.2019

Endoscopy 2019; 51: E380-E381

(c) Georg Thieme Verlag KG

Stuttgart · New York

ISSN 0013-726X Center, 1441 N Beckley St., Dallas, Texas 75203-1201, United States

Fax: +1-214-947-3895

nateavila@gmail.com

\section{ENDOSCOPY E-VIDEOS}

https://eref.thieme.de/e-videos

回发政 Endoscopy E-Videos is a free access online section, reporting 回: on interesting cases and new techniques in gastroenterological endoscopy. All papers include a high quality video and all contributions are freely accessible online.

This section has its own submission website at

https://mc.manuscriptcentral.com/e-videos 